\title{
Rational Framework Based Model of Applying Six Sigma Principles For Integrated Human Resource and Operations Management
}

\author{
S. Ananth, A.Varadaraj
}

\begin{abstract}
In any organization, management is considered to be successful, only if there is a reduction in uncertainty, to a great extent. These uncertainties are reduced by the system design, analysis and implementation effectively by human resources. Human resource management, unlike other operations in the organization is a very sensitive activity and not all the things in HR management can be quantified and spoken in terms of data and numbers. On the other hand, Operations management, in an organization where exact productivity, profit and loss are dealt with in a critical form, should be handled with a system and application that provides proper numbers and data from various operations. Operation management requires technical knowledge about the system in study or implementation, whereas HR management deals with the sensitive human resources as much of the job can't be quantified such as employee happiness. In many organizations, it is evidently proved that the application of six sigma has led to the visible improvement in the holistic quality of the entire operations as well as individual process. In the initial stages, leaders in HR management were of the opinion that six sigma is principle, that is quite inappropriate towards HR management. After so many deliberations and speculations, many literatures and implementations have proved that six sigma can be ported into HR operations for better efficiency and enhancements in terms of quantifiable aspects. In this research article, we have made a novel move, in integrating the various aspects of Operations management and HR management using six sigma model, that will eventually create an ambience that is conducive for all the human resources to experience in an organization. This framework deals with the integration and analysis of every step towards quality improvement process by six sigma with Operations management and HR management.
\end{abstract}

Keywords: Data, Process, Six Sigma, Human Resource, Operations, Efficiency, Total Quality Management

\section{INTRODUCTION}

In any organization, two departments that play a key role in its success are human resource and operations. Human resource management definitely needs to tackle with lots of intangible elements unlike operations management principles, which deals primarily with tangible operations and effects associated with it. The functions of human resource division in any organization are to hire, train, motivate and retain workforce within the organization. Motivation is the biggest factor that often needs to persistently exist in an organization and that often perish

Revised Manuscript Received on July 10, 2019.

Dr. S. Ananth, Assistant Professor, Alliance School of Business, Alliance University, Bangalore, Karnataka, India. (email ananth72@gmail.com)

DR. A. VARADARAJ, Professor, Alliance School Of Business, Alliance University, Bengaluru, Karnataka, India (E Mail: Avraj28@Gmail.Com) within the employee of the organization. Strategically speaking , HRM should frequently conduct ice breaking programmes, cross cut relationships, get together and directly or indirectly insist the work culture that is maintained in the organization. Apart from this, HRM should also devise and implement strategies to monetarily benefit the employees at periodical intervals, as to maintain the standard of living of their employees. Two broad functions that are included in the HRM are Managerial functions and operations functions. Managerial functions include planning, organizing, directing and controlling. Operative functions include Recruitment/Hiring, Job analysis and design, performance appraisal, training and development, salary administration, employee welfare, and labor welfare.

Operations management in an organization is referred in early days as production management. Operations management refers to all the best practices in the organization that leads to maximization of Return on Investment. The various tasks involved in operations management include planning, organizing and supervising processes in order to increase the profitability. Operations management is now considered to be a multi functional discipline area that includes even finance and marketing operations. For effective operations management, knowledge and skill sets in multi disciplinary area is required. There were many theories from Henry Ford to Taylorism, available in todays literature that deals with effective operations management.

This paper makes a novel effort to analyze the effects of integrating HR and operations management through six sigma principles. Section 2 of this paper deals with the related literature that had already handled the integration of HR and operationsmanagement. Section 3 of the paper deals with the principles of six sigma and section 4 focusses on the effects of six sigma with respect to the intangible and tangible factors of HR and Operations integration. Section5 of the paper deals with the conclusion and future work.

\section{RELATED STUDY:}

Various literatures are available that dealt with the integration of human resource management and operations management in detail. This section of the paper deals with 


\section{RATIONAL FRAMEWORK BASED MODEL OF APPLYING SIX SIGMA PRINCIPLES FOR INTEGRATED HUMAN RESOURCE AND OPERATIONS MANAGEMENT}

the important points on those recent literatures that have discussed upon this important area of research under the management domain. John Boudreau et al., [1] dealt with the interface between HR and operations management. It deals with behavioral insights, contextual insights and translation, experimentation and integration. The various insights will be applied towards translation for better understanding of each fields'corresponding paradigms and approaches. Experimentation part of the interface will deal with the particular insights that hold significance in the integration approach. Then finally integration is carried out as part of the promising approaches between two divisions.

Kamal Birdi et al., [2] focussed on the impact of HR and operations management integration on company productivity. The work done by the authors studied the relative merits of the integration with the help of practices adopted in 308 companies over a period of 22 years and found that empowerment and extensive training to human resources gained much of the productivity attention to all the organization.

Ruth Mayhew et al., [3] dealt with the conflicts between HR and Operations management. The conflicts discuss about the division of responsibilities and line of authority. Wherever human resource managers provide consultancy to line managers, the model of the business is in such a way that operations managers get larger control of the employees and greater latitudinal control over their staffing issues. Consistent application of workplace policies is the top most priority of any human resource divisional staff. That is where most of the operations manager find odds with the HR managers.

Lilian M.de Menezes et al., [4] focussed on the performance link with the integration of human resource and operations management. This research has utilized the 34 years of data obtained from the UK based companies on HRM and OM integration practices. Ordered restricted latent class models are utilized in deriving three longitudinal latent clusters. Longitudinal nature of the data permitted the modeling of the growth curves of each practices and the result has shown that pioneers are more productive than any other practices and that integration of HRM and OM practices have paid off well.

Josie J.Trine et al., [5] suggested that HR shared services operations model has to interact with more of the outside departments than HR core team. Interview dialogues and survey results have suggested three important reporting structures for the HR operations sub systems functions. The three structures are HR operations within shared services and support, HR as a center of excellence and HR operations embedded among HR generalist support.

Softscape's whitepaper [6] discussed the various HR process integrations that provide organizations with the most business value. The top five HR process integrations are Employee development and succession planning, Learning management, Performance management, Reporting and Core HR, compensation management. This research has clearly revealed that the business value can be achieved by integrating $\mathrm{HR}$ and talent processes, systems and data.

Rosemary Batt et al., [7] dealt with service strategies, marketing operations and HR practices in private sector service industries through the interaction with employees and customers. There is also growing empirical evidence that companies that compete on the basis of customer quality and customization do generate higher revenues and profits.

Peter Boxall et al., [8] focused on the scope of HRM and its major sub fields. The sub fields include Micro HRM (MHRM), Strategic HRM (SHRM) and International HRM (IHRM).

\section{SIX SIGMA AND PROBLEM SOLVING}

From the times of human evolution, man is a social animal and he is good at developing problem solving strategies. For any problem, solution can be developed by and large using common sense. This common sense methodology has to be framed into a step by step solution for everyone to adopt. As a matter of fact, one such problem solving technique to improve the quality of any operation within the organization is SIX SIGMA. Six sigma principles consists of DMAIC process in which various phases such as Define Phase, Measure phase, Analyze phase, Improve phase and Control phase are involved.

It follows a simple approach in problem solving, which can be state using the equation [9]

$\mathrm{Y}=\mathrm{f}(\mathrm{x}) \ldots \ldots . .(1)$

Where $\mathrm{Y}=$ the effect

$\mathrm{X}=$ the input

$\mathrm{F}=$ function that associates the input and effect

Six Sigma philosophy has been used to develop system dynamics model for various divisions within the organization. Manufacturing process has received lots of attention from the six sigma fraternity in the development of various optimized model for the increased productivity.

A fish bone diagram from Ishikawa, which is shown below is a classical example of relationship between cause and effect [10]. It is considered to be a cause analysis tool that identifies various causes and the associated effect of those problems. This fishbone diagram has been meticulously converted to a philosophy called as Six Sigma problem solving.

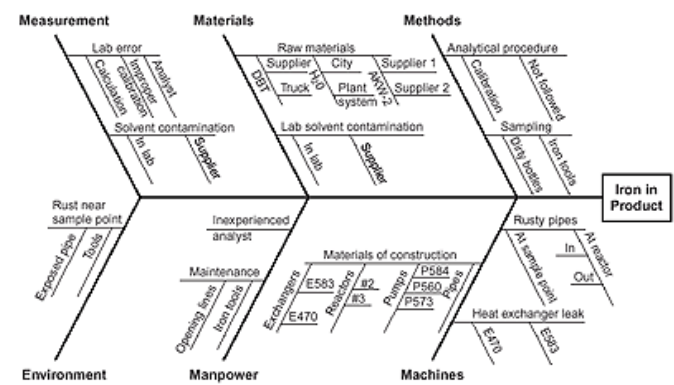

Fig.1 Fish Bone-Ishikawa Diagram

Gutierraz et al 2004.[11], state that the six sigma philosophy is a continuous quality improvement strategy within an organization to identify the causes of errors and eliminate them to a maximum possible. Six sigma is basically an application of mathematical tools and statistical 
formulas to eliminate defects, reduce variations ina process or product. Basically six sigma is denoted by the statistical measure called as standard deviation. Six sigma analysis must use both descriptive statistics and inferential statisitics.

The average value of the data is called the mean or X-bar. The equation for the mean is

$(\mathrm{X} 1+\mathrm{X} 2+\mathrm{X} 3+\ldots+\mathrm{XN}) / \mathrm{N}$

Process potential denoted by $\mathrm{Cp}$ is related to system tolerance and process variation (standard deviation). The equation for $\mathrm{Cp}$ is

$\mathrm{Cp}=(\mathrm{USL}-\mathrm{LSL}) / 6 \sigma$

Where

USL denotes Upper specification limit and

LSL denotes Lower Specification limit and sigma in the denominator denotes standard deviation. It is calculated using the below formula.

$$
\sigma^{2}=\Sigma(\mathrm{X}-\mu)^{2} / \mathrm{N}
$$

\section{ANALYTICAL FRAMEWORK BASED MODEL OF APPLYING SIX SIGMA IN INTEGRATED HR AND OPERATIONS MANAGEMENT \& RESULTS}

This section of the paper presents our work in which six sigma can be applied for integrated HR and Operations management activities. We strived in all dimensions to apply the principles of six sigma to present the following analytical framework based model for the process of critical integration of HR and operations management activities. The model is presented below and the discussion follows the diagram.

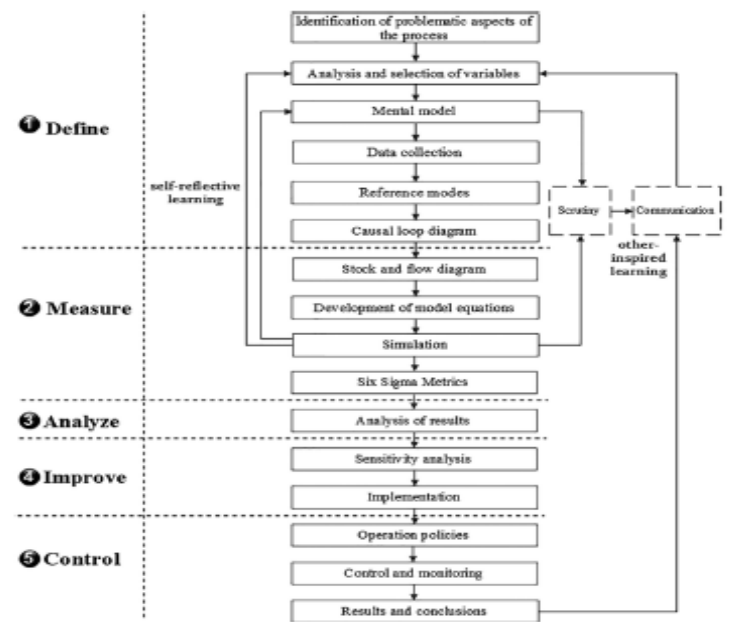

Fig.2. DMAIC model for Integration of HR and Operations Management

The first and foremost step in the define process is the identification of the problematic aspects of the process. After identification, appropriate data collection should be done to take care of the analysis of the integration. Self reflective learning is made as part of the define process of six sigma.

Development of model equation should be carried out with the help of various aspects of Human resource and operations management activities. Especially the model equation should incorporate the final intangible goals of Employee satisfaction and customer satisifaction to the core.
This model equation must be simulated in the organization of concern and the six sigma metrics must be calculated as provided in section III. Once the metrics values are computed, they must be analyzed for the benchmark expected values and if they are better, it must be left as such or it should be subjected to improvement through adjustment of certain parameters which are measurable and certain non parametric analysis should be carried out. This should be done through sensitivity analysis. This sensitivity analysis if found to be giving appropriate values, must be implemented with operational policies and monitoring and control procedures. Other learning models shall be utilized along with self reflective learning to take control of the integration of human resource and operations management using six sigma problem solving approach.

\section{CONCLUSION AND FUTURE WORK}

In this paper, a novel effort is undertaken to integrate the processes involved in human resource and operations management. This effort is utilized in creating an analytical framework based model for the application of six sigma problem solving philosophy. DMAIC approach with step by step process of integration is given in the paper. Also, the future work involved shall be the application of this analytical model in a concept organization and simulate it in a small scale to know the results obtained and further improve on the model with tangible and intangible metrics.

\section{REFERENCES}

1. John Boudreau, Wallace Hopp, John O. McClain, L. Joseph Thomas, (2003) On the Interface Between Operations and Human Resources Management. Manufacturing \& Service Operations Management 5(3):179-202. https://doi.org/10.1287/msom.5.3.179.16032

2. Birdi.K, Clegg.C, Patterson.M, "The impact of human resources and operational management practices on company productivity- A longitudinal study", Personal Psychology, 2008, 467-501

3. Ruth Mayhew, " Conflicts between Human resource and operations management"- Web resource

4. L.M.de Menezes, Wood.S, Gelade.G, " The integration of human resource and operations management practices and its link with performance- A latent longitudinal class study", Journal of Operations Management , 2010, pp.455-471 (2012), "Integrate HR with operating strategy", Human Resource Management International Digest, Vol. 20 Issue: 2, https://doi.org/10.1108/hrmid.2012.04420baa.005.

5. Josie J.Trine, " HR Operations: Adding Value by driving Effective and Efficient HR service delivery", whitepaper by Scapesoft, 2010

6. R.Batt" Service strategies marketing, operations and HR practices", Digital Commons ILR, Cornell Library, 2007

7. Peter Boxall, John Purcell, and Patrick M. Wright, "Human Resource Management: Scope, analysis and Significance", The Oxford Handbook of Human Resource Management, 2008

8. [https://www.knowledgehut.com/blog/quality/six-sigmamethods-and-formulas-for-successful-quality-management

9. https://asq.org/quality-resources/fishbone

10. Gutiérrez H.y De la Vara R. (2004). Control Estadístico de Calidad y Seis Sigma. Mc Graw Hill Interamericana Editores, S.A. de C.V. México, D.F.

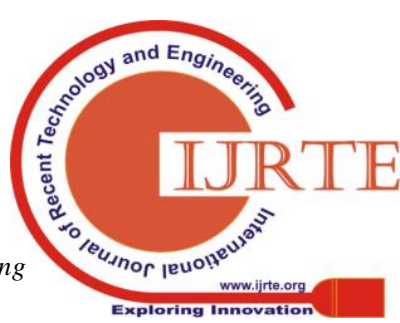

